Cahiers $d u$ MONDE RUSSE

\section{Cahiers du monde russe}

Russie - Empire russe - Union soviétique et États indépendants

$46 / 4 \mid 2005$

L'invention d'une politique humanitaire

\title{
Ivan Savický, Osudová setkání
}

\section{Stéphanie Cirac}

\section{OpenEdition \\ Journals}

Édition électronique

URL : https://journals.openedition.org/monderusse/6673

DOI : $10.4000 /$ monderusse. 6673

ISSN : $1777-5388$

Éditeur

Éditions de l'EHESS

Édition imprimée

Date de publication : 1 décembre 2005

Pagination : 986-989

ISBN : 2-7132-2057-2

ISSN : $1252-6576$

\section{Référence électronique}

Stéphanie Cirac, «Ivan Savický, Osudová setkání », Cahiers du monde russe [En ligne], 46/4 | 2005, mis en ligne le 30 juin 2009, consulté le 03 septembre 2022. URL : http://journals.openedition.org/ monderusse/6673; DOI : https://doi.org/10.4000/monderusse.6673

Ce document a été généré automatiquement le 3 septembre 2022

Tous droits réservés 


\title{
Ivan Savický, Osudová setkání
}

\author{
Stéphanie Cirac
}

\section{RÉFÉRENCE}

Ivan SAVICKÝ, Osudová setkání. Češi v Rusku a Rusové v Čechách, 1914-1938 [Les rencontres du destin. Tchèques en Russie et Russes en Bohême, 1914-1938] Prague :

Academia, 1999, $272 \mathrm{p}$.

1 Dans cet ouvrage, Ivan Savický décrit les relations tchéco-russes de 1914 à 1938 à travers le prisme de l'émigration. Analysant la présence tchèque en Russie puis russe en Tchécoslovaquie, l'auteur s'interroge sur l'influence qu'ont pu avoir ces communautés exilées sur leur nouvel environnement. Il présente ainsi ces exils comme un jeu de miroirs: à travers l'émigration russe, ce n'est pas uniquement la Russie qui est appréhendée, mais aussi l'histoire de la Tchécoslovaquie, dans son rapport au grand voisin ainsi qu'au reste de l'Europe. Au-delà, Savický met en évidence les constructions dont chacune de ces communautés a été l'objet à travers les catégories établies par les États d'accueil, afin d'une part de gérer leur flux et d'autre part de les utiliser au mieux.

2 La première partie de l'ouvrage est consacrée aux Tchèques en Russie jusqu'aux années 1920, elle se concentre essentiellement sur l'aventure de la Légion tchèque tandis que la deuxième a pour objet l'émigration russe pendant l'entre-deux-guerres en République tchécoslovaque.

3 Dès les années 1860, les premières colonies tchèques s'installent en Volhynie où l'on compte à la fin du siècle 28000 Tchèques. Ceux-ci, agriculteurs pour la plupart, ont été attirés par le prix des terres, le gouvernement russe accordant des rabais considérables aux nouveaux venus. D'autres groupes socioprofessionnels suivront, censés transmettre leur savoir-faire dans le domaine de la brasserie, de la restauration, mais aussi de l'enseignement, de la musique entre autres); ils sont techniciens, ouvriers qualifiés, cadres et s'installent sur tout le territoire de la Russie. Des Sokol (associations sportives et culturelles galvanisant l'identité nationale tchèque) sont implantées jusqu'en Sibérie et 
sensibilisent les Russes à la question tchèque. Celle-ci devient un facteur de rapprochement entre les deux peuples.

4 Alors que la plupart des Tchèques prospèrent sur le sol russe, la Première Guerre mondiale révèle l'ambiguïté de leur situation: tout en s'intégrant, ils sont demeurés sujets de l'empire austro-hongrois. Auparavant immigrés dans le sens où un retour était toujours possible, avec la guerre, ils vont rejeter leur appartenance autrichienne en prenant parti contre l'empire bicéphale. Ils sont désormais des émigrés et ne peuvent envisager de regagner l'Autriche-Hongrie. C'est ainsi que la conscience nationale déjà développée s'exacerbe : le Conseil des Tchèques en Russie (Rada Čechů v Rusku) est fondé le $1^{\text {er }}$ septembre 1914. De même, des unités militaires sont constituées en Ukraine afin de soutenir l'effort de guerre côté russe. Rapidement, Tomas G. Masaryk entend profiter de ces forces armées qu'il ne souhaite pas voir rester sur le front russe. Bien que le tsar, dans son « Appel au peuple tchèque » (dès septembre 1914), ait été le premier parmi les Alliés à reconnaître publiquement l'identité tchèque, Masaryk n'a guère confiance en l'empire russe et se défie de la russophilie de ses proches. Il préfère rattacher à l'armée française ces forces qui formeront la Légion tchèque afin d'affirmer son loyalisme vis-à-vis des Occidentaux et tenter de peser dans les négociations de paix. Or cette jeune armée aura une évolution fort éloignée de ses attentes.

5 C'est pour veiller à l'organisation et au transfert de la Légion vers la France que Masaryk se rend en 1917 en Russie où il séjourne un an. À son retour, il rédige le Mémorandum de Tokyo qu'il remet à $\mathrm{T}$. W. Wilson. Il livre dans ce texte son analyse de la situation en Russie et les enjeux qui y sont liés à l'échelle de l'Europe. À travers ses réflexions se dessinent les premiers traits de sa "politique russe»: les Tchèques auraient un rôle à jouer dans la recherche d'un équilibre européen impossible à trouver avec une Allemagne ou une Russie trop puissantes, d'où la nécessité de voir les «petits peuples» slaves gagner leur indépendance. La stabilité de l'Europe dans son ensemble en dépendrait, tandis que pour la survie de l'État tchèque à venir, il serait indispensable que la Russie puisse être démocratique, même celle des bolcheviks, insiste-t-il.

Constituée des premières unités tchèques créées spontanément et rejointe par les déserteurs et les prisonniers de l'armée austro-hongroise (ceux-ci ne représentent guère plus du tiers des effectifs de la Légion car, contrairement au mythe des " frères slaves ", les prisonniers de guerre, même slaves, restent des soldats ennemis), cette armée finit par rassembler 50000 hommes. Ce qui importe à Masaryk, c'est qu'elle préserve sa neutralité. Toutefois, plus la guerre civile progresse, plus les Tchèques - soldats et officiers finissent par ignorer les ordres du Conseil national tchécoslovaque (ČSNR). Celui-ci exige dès le mois de mai 1918 que les légionnaires remettent leurs armes aux bolcheviks, censés dès lors assurer leur protection (ce que ne peuvent accepter les Tchèques qui nourrissent une méfiance soutenue à l'égard des Soviétiques, bien réciproque d'ailleurs). Dans ces conditions, l'armée française, craignant l'incident diplomatique, se détache d'une Légion désormais incontrôlable. Le capitaine Radol Gajda ne peut que se réjouir de ce virage. À la tête d'une partie des troupes tchèques auxquelles il incorpore des soldats russes, l'officier, qui ne peut se satisfaire d'un accord avec l'Armée rouge, a déjà développé des contacts avec les forces contre-révolutionnaires.

7 La Légion n'est donc plus supposée regagner le front français, d'autant que la guerre touche à sa fin; son objectif est de soutenir les forces démocratiques en Russie, éventuellement avec l'aide d'une intervention étrangère. Le 7 septembre, $900 \mathrm{~km} \mathrm{du}$ Transsibérien sont déjà sous son contrôle ; 6 mois plus tard, celui-ci s'étend sur $4400 \mathrm{~km}$. 
La Légion est soutenue financièrement par l'Occident; dès juillet 1918, elle est autosuffisante, dispose de plusieurs convois ferroviaires -dont certains trains commerciaux - et se déplace avec son bétail.

8 Cette relative aisance finit par lui valoir des jalousies d'autant plus virulentes que l'alliance tchéco-russe faiblit. La Légion, par sa volonté d'imposer la démocratie (largement battue en brèche par la guerre civile), provoque l'ire des Cent-noirs, qui professent une idéologie d'extrême droite partagée par un certain nombre d'officiers de l'armée blanche. Ces derniers accusent le Gouvernement Provisoire panrusse d'être soumis aux Tchèques dont les espoirs s'évanouissent définitivement avec l'arrivée au pouvoir de l'amiral Kolãak (novembre 1918). Cependant, bien qu'isolés, les légionnaires demeurent une force militaire non négligeable qui, après moult revirements, finira par arrêter Kolãak - qu'une partie des troupes tchèques avait rallié avant de le remettre à ses ennemis qui l'exécuteront. Passé cet épisode fort trouble, la Légion tchèque est rapatriée. D'aucuns verront dans sa trahison un moyen de garantir ce retour, d'autres, le signe de son extrême solitude.

9 Malgré ses efforts, la Légion aura eu du mal à protéger les forces démocratiques exilées en Sibérie et les attentes de Masaryk seront déçues. Néanmoins, l'aventure tchèque aura permis à ce dernier de s'affirmer sur la scène politique européenne ; et la Légion, bien que n'ayant pas joué le rôle qu'on lui destinait, se sera avérée un atout non négligeable pour définir sa "politique russe». Cette dernière n'était pas mue par des sentiments russophiles mais par la vision masarykienne de l'Europe selon laquelle les rapports russotchèques inscriraient la République tchécoslovaque dans l'espace européen.

10 L'accueil de l'émigration russe constitue le deuxième volet de cette politique. Le premier dépendait d'institutions qui relevaient de différents États dont les intérêts divergeaient : la République tchécoslovaque encore inexistante, la France, la Russie tsariste puis soviétique, le Gouvernement Provisoire panrusse. De la même façon, la communauté russe en exil à Prague se regroupait autour d'organes issus de l'émigration (Ruská Jednota [Unité russe], Zemûdelska Jednota [Unité agricole] pour les paysans et le Zemgor) et, dans le même temps, était contrôlée par le ministère tchécoslovaque des Affaires étrangères.

11 L'émigration fit l'objet d'une catégorisation. Les autorités tchécoslovaques garantissaient aux exilés russes un accueil exceptionnel pour l'Europe d'alors (il fut toutefois jugé insuffisant par les partisans tchèques de la monarchie russe), offrant un soutien financier à ceux qui relevaient des catégories définies (des bourses sont attribuées aux étudiants, savants et écrivains quel que soit leur pays de résidence). Cette politique obéissait à deux logiques. Elle ne relevait pas tant de la bienfaisance ou de considérations humanitaires que d'une volonté de réguler les flux migratoires dans l'optique de la construction du jeune État tchécoslovaque. Si, en 1920, 800 étudiants sont accueillis, 4000 agriculteurs (dont $50 \%$ sont des cosaques) reçoivent un visa. Cette sélection montre qu'à travers le traitement de l'émigration, les besoins du pays entrent en ligne de compte : que la plupart des élus aient été des paysans témoigne du manque de main-d'œuvre agricole. Des raisons politiques ont également motivé ce choix : la petite paysannerie russe était perçue comme l'héritière des mouvements paysans favorables aux courants démocratiques. Au-delà de ces questions intérieures, l'accueil des Russes recouvrait des visées stratégiques, à savoir la recherche d'une influence sur la Russie soviétique en formant une élite intellectuelle et politique qui, pensait-on, y retournerait sous peu. Masaryk voulait faire de sa capitale le « centre des Russes progressistes ». C'est pourquoi il soutint essentiellement les Socialistes Révolutionaires (SR), par le biais de la 
presse que ces derniers dirigeaient -Volja Rossii- largement subventionnée à la différence de celle de leurs concurrents.

12 La " politique russe » était donc un véritable jeu d'équilibre consistant à naviguer entre les différentes tendances de la scène politique tchèque. Il s'agissait pour Masaryk de ne pas s'aliéner le soutien de la gauche procommuniste, sans l'appui de laquelle la socialdémocratie n'aurait pu gouverner. Cette unité politique était garante de l'indépendance de l'État (encore fragile, ce que démontreront les Accords de Munich). Masaryk fit preuve de pragmatisme en conciliant les diverses composantes politiques qui, chacune, avait sa propre analyse de la situation soviétique et de l'émigration.

En définitive, l'émigration russe ne fut pas transitoire. La perspective d'un retour au pays s'éloignant, les Russes durent tenter de s'insérer, ce qui était difficile en raison notamment du chômage massif des années 1930. Nombreux furent ceux qui choisirent d'émigrer de nouveau. Quant à la communauté scientifique, une partie d'entre elle s'adapta, cherchant à s'inscrire dans une dimension nationale, voire internationale.

14 Ivan Savický rappelle en conclusion combien l'historiographie a évolué au sujet des relations russo-tchèques et à quel point elle est encore fluctuante en Russie. Son ouvrage s'adresse à une large communauté de lecteurs en République tchèque où cette question est aujourd'hui revisitée. Au lecteur qui pourrait s'étonner de l'absence d'appareil critique, une postface précise qu'une partie des sources relatives à l'émigration russe est tirée de l'histoire personnelle de l'auteur. Le spécialiste de l'émigration russe étaie son analyse des faits rigoureuse de réflexions personnelles et originales, illustrant l'imbrication entre les mémoires individuelle et collective. En effet, ce livre, fruit de longues recherches, n'a pas été conçu comme un ouvrage universitaire classique et c'est peut-être aussi ce qui en fait l'intérêt. 